\title{
Comparison of Acoustic and Auditory-Perceptual Evaluation in Sustained Vowel and Connected Speech by Glottal Closure Pattern in Voice Disorders
}

\author{
Eun-Jung Lee ${ }^{\mathrm{a}}$, Jaeock Kim ${ }^{\mathrm{b}}$ \\ ${ }^{a}$ Dr. Rho's Head \& Neck-Thyroid Clinic, Seoul, Korea \\ ${ }^{b}$ Division of Speech Pathology Education, Graduate School of Education, Kangnam University, Yongin, Korea
}

Correspondence: Jaeock Kim, $\mathrm{PhD}$

Division of Speech Pathology Education, Graduate School of Education, Kangnam University, 40 Gangnam-ro, Giheung-gu, Yongin 16979, Korea Tel: $+82-31-280-3221$

Fax: +82-31-280-3479

E-mail: jaeock@gmail.com

Received: April 4, 2020

Revised: May 17, 2020

Accepted: May 21, 2020

his work was based on the master's thesis of the first author and was supported by the Ministry of Education of the Republic of Korea and the National Research Foundation of Korea (NRF2018S1A5A2A03032902)

This work was also partly presented at the 2018 Fall Conference on Korean Society of Speech Sciences.
Objectives: This study classified voice disorders into hyper-functional (Hyper) and hypofunctional voice disorder (Hypo) by glottal closure pattern and compared acoustic and auditory-perceptual evaluation in sustained vowel and connected speech. Methods: The participants consisted of 46 patients in the Hyper group and 46 patients in the Hypo group. Data were collected through sustained vowel /a/ and connected speech (reading the "Autumn" paragraph) and were analyzed with cepstral analysis (CPP, mean CPP $\mathrm{F}_{0}$, and L/H ratio) for acoustic evaluation, and GRBAS scales for auditory-perceptual evaluation. Results: In the acoustic evaluation, CPP was higher in the sustained vowel than in connected speech, however the mean CPP $F_{0}$ was the opposite. CPP was higher in the Hyper group than the Hypo group and the mean CPP $F_{0}$ was higher in the Hypo group. In the auditory-perceptual evaluation, the two groups were distinguishable on the $B$ and $A$ scale, but were not different on the $R$ and $S$ scale. In addition, in both groups, the GRBAS scale was significantly negative correlated with CPP and L/H ratio in both sustained vowel and connected speech. Conclusion: This study revealed that it was possible to identify voice disorders through acoustic and auditory-perceptual evaluation using a combination of sustained vowel and connected speech. These evaluation methods are helpful to discriminate compensatory strategies for glottal incompetency in hypofunctional voice disorder.

Keywords: Voice disorder, Glottal closure pattern, Sustained vowel, Connected speech, Cepstral analysis, Auditory-perceptual voice evaluation
음성장애란 모든 형태의 음성적인 일탈을 일컫는 용어로서, 전 통적으로 음성장애를 발생학적 원인에 따라 기능적, 기질적, 그리 고 신경학적 음성장애로 분류한다. 그러나 성대결절이나 성대폴립 등과 같이 음성남용이나 음성오용 등의 기능적 원인이 기질적 성대 병변을 초래하기도 하고, 신경학적 원인으로 기인된 성대마비의 경 우 성대의 불완전 접촉에 대한 보상작용으로 기능적 음성장애가 동반되기도 한다. 이에 임상에서의 음성치료는 병인론적 구분에 의 한 질환명에 따라 다른 치료방법을 적용하기보다는 발성 시 성대의 접촉양상이나 긴장성에 따라 차별화된 치료방법을 사용한다. 성대 를 과도하게 접촉하고 후두의 긴장이 높음으로 인해 음성장애가 초래된 경우에는 후두를 이완하여 발성하는 음성치료를 적용하는
반면, 성대가 불완전하게 접촉하고 후두의 긴장도가 감소함으로써 음질의 이상이 초래된 경우에는 성대의 접촉을 증가시키는 음성치 료를 실시한다(Boone, McFarlane, Von Berg, \& Zraick, 2014; Carole, 2014). 그러므로 임상적 적용의 큰 틀에서는 병인론에 기인한 음성장애 분류보다는 성대접촉 양상과 후두의 긴장성 여부에 따 라 분류함으로써 보다 효율적인 음성치료를 적용할 수 있을 것이 다. 선행연구에서도 후두의 기질적 병변이 없고 기능적으로 문제가 있는 경우에만 기능적 발성장애(functional dysphonia)라고 하던 정의에서 그 의미를 좀 더 확장하여 후두의 기질적 또는 신경학적 이상 유무에 상관없이 성대접촉 양상과 후두 긴장성에 따라 과다 기능적(hyperfunctional) 또는 과소기능적(hypofunctional) 음성 
장애라고 분류하기도 하였다(Szkie łkowska, Krasnodębska, Miaśkiewicz, \& Skarżyński, 2018; Watts \& Awan, 2011).

음성장애를 평가하는 방법에는 청지각적 평가, 음향학적 평가, 공기역학적 평가, 내시경을 이용한 시각적인 평가 등의 다양한 방법 이 있다. 이 중에서도 청지각적 평가의 하나인 GRBAS 척도는 평가 항목의 구조가 단조롭고 쉬워 빠른 검사가 가능하여 임상현장에 서 많이 사용되고 있다. 그러나 음도, 억양, 음성 떨림, 음성 크기 변 동, 공명 등을 명확하게 판단하기 어렵고, 주관적인 평가이기 때문 에 신뢰도가 낮을 수 있다는 단점이 있어(Lee \& Shin, 2010; Sohn, 2008), 단독으로 사용하기 보다는 상호 보완적인 평가방법들을 혼 용할 필요가 있다. 음향학적 평가로는 크게 스펙트럼 분석과 캡스 트럼 분석이 있는데, 스펙트럼 분석(spectral analysis)이 일반적으 로 많이 사용된다(Shim, Kim, Kim, \& Shin, 2014; Yoo, Jung, Jang, $\& \mathrm{Ko}, 2003)$. 그러나 스펙트럼 분석은 시간을 기반으로 한 분석 (time-domain based analysis)이기 때문에 음성파형의 주기성이 특 정되는 경우에만 분석이 가능하고, 성대가 불완전하게 접촉하거나 불규칙하게 진동할 경우에는 주기성 측정이 어려워 분석이 힘들 수 있다. 이에 최근에는 기본주파수 추출 기반이 아닌 큐프렌시 기반 분석(Quefrency-domain based analysis)으로 소음 성분이 많은 음 성 신호도 정량적으로 분석이 가능한 캡스트럼 분석(cepstral analysis)에 대한 관심이 높다(Carding et al., 2004; Choi \& Choi, 2014; Hillenbrand \& Houde. 1996). 캡스트럼 분석은 전체 신호음 중 조화음(harmonics)의 정도를 측정하는데, 음질문제가 심각하 여 음성신호의 주기성이 떨어질 경우 스펙트럼 분석에 비해 민감도 와 특이도가 높다(Lowell, Kelley, Awan, Colton, \& Chan, 2012; Watt \& Awan, 2011). 캡스트럼 분석의 측정변수로는 캡스트럼 최 고 정점(cepstral peak prominence, $\mathrm{CPP}$ ), $\mathrm{CPP}$ 평균 주파수(mean $\mathrm{CPP} \mathrm{F}_{0}$ ), 저주파수 대 고주파수 스펙트럼 에너지 비율(ratio of low to high-frequency spectral energies, $\mathrm{L} / \mathrm{H}$ ratio) 등이 있다(Lee, Lee, \& Choi, 2018; Seo \& Seong, 2013; Watt \& Awan, 2011; Yu, Choi, Choi, \& Choi, 2018).

$\mathrm{CPP}$ 는 전체 신호음 중 조화음(배음)의 정도를 하나의 정점 (peak)으로 나타내는 측정치로서 음질을 구별하는 데 매우 중요하 며, 비주기적 신호가 많은 음성일수록 CPP가 낮아진다(Lee, 2019; Watt \& Awan, 2011). Mean CPP F 는 조화음(harmonics) 중 가장 큰 에너지를 갖는 $\mathrm{CPP}$ 의 주파수로, 산출된 음성신호 중 유성음의 $60-300 \mathrm{~Hz}$ 범위에 해당하는 CPP의 평균 주파수를 의미한다(Hillenbrand, Cleveland, \& Erickson, 1994). Mean CPP Fo는 성대의 긴 장이 증가할수록 커지고, 쥐어짜는 정도와 관련이 있어 성대가 불 완전 접촉하여 나타나는 기식성(breathy) 음성에서는 그 수치가 낮
고 성대가 과도하게 접촉하는 긴장성(strained) 음성에서는 높게 나 타나 발성유형에 영향을 받는다(Hammarberg, Fritzell, Gauffin, Sundberg, \& Wedin, 1980; Lowell et al., 2012). L/H ratio는 $4 \mathrm{kHz}$ 주파수 대역을 기준으로 고주파에너지에 대한 저주파에너지의 비 율을 나타내며, 고주파수 영역에서 소음성 에너지가 높은 기식성 (breathy) 및 거친 음성(rough)과 관련이 높다(Seo \& Seon, 2013; Watts \& Awan, 2011). 선행연구에 따르면, 식도발성 화자는 정상인 에 비해 $\mathrm{CPP}$ 와 $\mathrm{L} / \mathrm{H}$ ratio는 낮으나 mean $\mathrm{CPP} \mathrm{F}_{0}$ 는 높으며(Shim et al., 2014), 내전형 연축성 발성장애 화자는 중증도가 높을수록 $\mathrm{CPP}$ 와 L/H ratio가 감소하였다(Shim et al., 2016). 반면 마비말장애 와 같이 긴장성과 기식성이 섞여있는 경우에는 두 개의 상반된 음 질특성으로 인해 변별적 특성이 중화되어 $\mathrm{L} / \mathrm{H}$ ratio가 정상화자와 의 유의한 차이가 없어 음질평가에 있어서의 L/H ratio의 유용성이 낮다고 보고되기도 한다(Seo \& Seong, 2013).

이렇게 음질 분석과 관련된 측정치들은 발성 시 긴장성이나 기식 성 등에 따라 다르게 나타날 수 있으므로 음성장애의 발생학적 원 인과 상관없이 음성산출 시 성대접촉의 기능적 양상과 후두의 긴 장성에 따른 차이를 살펴볼 필요가 있다. 국외 선행연구들에서도 성대접촉 양상에 따라 음성장애 집단을 구분하여 그 특성을 비교 하거나 각 집단의 음향학적 특성을 연구한 경우들이 있다(Bonilha, White, Kuckhahn, Gerlach, \& Deliyski, 2012; Szkie ł kowska et al., 2019; Watts \& Awan, 2011). 그러나, 국내에서는 병인론적 구분 에 따른 음성장애 간의 차이를 비교하거나 과도한 성대접촉에 국 한된 연구들이 대부분이다(Chung et al., 2002; Jin, 2014; Kim \& Lee, 2017; Kim, Lee, Choi, \& Choi, 2017; Lee, Yoo, \& Park, 2019; Shim et al., 2016). 이에 발성 시 후두를 긴장하여 성대가 과도하게 접촉하는 경우와 성대가 불완전하게 접촉하거나 이완된 경우와 같 이 발성 시 후두의 양상이 다르게 나타나는 음성장애를 평가하고 이들 간의 차이를 비교하는 것은 매우 의미가 있을 것이다.

음성평가에 사용되는 발화과제 유형 중 모음연장발성은 개인의 발화 특성이나 문맥, 강세와 같은 음질 요인들의 변동이 적어 연속 발화에 비해 통제된 상황의 음성을 평가할 수 있고(Parsa \& Jamieson, 2001), 연속발화는 발성의 시작과 끝, 음성일탈, 주파수와 진폭 의 변동 등의 특성이 포함되어 있어 실제적이고 일반화된 음성평가 를 실시할 수 있다(Parsa \& Jamieson, 2001). 선행연구에 따르면, 음 성장애 증상은 연속발화상에서 잘 나타나며(Roy, Gouse, Mauszycki, Merrill, \& Smith, 2005; Yui, Worrall, Lonland, \& Mitchell, 2000), 발화 과제 유형에 따라 청지각적 음성평가의 차이를 보이기도 한다(Roy et al., 2005; Shin, Hong, \& Sim, 2011). 이처럼 발화과제 유형에 따라 청지 각적 또는 음향학적 음성평가 결과의 차이가 있을 수 있기 때문에 대 
Eun-Jung Lee, et al. • Voice evaluation in Sustained Vowel and Connected Speech by Glottal Closure Pattern COMMUNICATION SCIINCES \& DISORDERS

상자특성에 따른 적절한 발화과제를 사용할 필요가 있다.

이에 본 연구는 기능적 음성장애의 전통적 분류인 과다기능적 (hyperfunctional) 및 과소기능적(Hypofunctional) 음성장애의 의 미를 좀 더 확장하여 음성장애를 발화 시 후두 긴장과 함께 과도한 성대접촉을 보이는 과다기능성 집단(Hyper)과 후두 긴장의 약화 나 불완전 성대접촉을 보이는 과소기능성 집단(Hypo)으로 분류하 고, 이들 간에 발화과제 유형(모음연장발성 vs. 연속발화)에 따른 청지각적 및 음향학적 음성평가의 차이를 살펴보고자 하였다. 또 한, 각 집단 내에서 청지각적 평가와 음향학적 음성평가가 어떠한 상관관계를 갖는지 살펴보고자 하였다.

\section{연구방법}

\section{연구대상}

서울 소재 대학병원 이비인후과에 내원하여 두경부이비인후과 전문의로부터 음성장애로 진단받은 208 명의 대상자 중에서 후두 스트로보스코피상에서 성대의 과도한 접촉과 후두의 과도한 긴장 으로 성대점막의 파동과 성대진동의 진폭이 감소하는 특성을 보이 는 경우를 Hyper 집단으로 분류하고, 현저한 성대의 불완전 접촉 으로 성대가 열린 기간(open phase)이 길거나 후두근의 긴장이 감 소하여 성대진동의 진폭이 증가한 경우를 Hypo 집단으로 분류하 였다(Szkie ł kowska et al., 2019). 두 집단의 양상이 함께 나타나 집 단 분류가 모호한 경우는 대상자에서 제외하였다. 음성장애 집단 의 분류는 경력 10 년 이상의 박사급 음성언어재활사 1 명과 언어치 료학과 교수 1 명이 함께 실시하였다. 또한 두 집단 간에 음성장애의

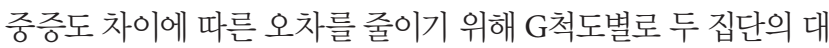
상자 수를 비교한 후, 대상자 수가 큰 집단에서 대상자 수가 적은 집 단의 수만큼 무작위로 추출하여 두 집단의 대상자 수를 동일하게 하였고, 본 연구에 최종적으로 포함된 대상자는 Hyper 집단 46명 과 Hypo 집단 46 명으로 총 92명이었다. 연령 분포는 Hyper 집단이
만 16-83 (평균 45.96)세였고, Hypo 집단이 만 12-82 (평균 51.28)세 로 두 집단 간 연령은 통계적으로 유의한 차이가 없었다. 본 연구의 대상자 정보는 Table 1과 같으며, 일차적 병인에 따른 음성장애 진 단명을 함께 제시하였다.

\section{자료수집}

모든 음성자료는 서울소재 대학병원 이비인후과 음성클리닉에 방문한 대상자들에게 음성평가 실시를 통해 녹음되었다. 녹음은 소음이 통제된 방에서 이루어졌으며, 대상자는 마이크와 $10 \mathrm{~cm}$ 간 격을 두고 앉은 후 평상시에 사용하는 편안한 음도와 강도로 음성 을 산출하였다. 대상자는 발화과제 유형(과제)에 따라 모음연장발 성 자료는 모음 / 기를 3초간 발성한 후 분석을 위해 처음과 마지막 을 제외한 가운데의 안정적인 1 초를 편집하였고, 연속발화 자료는 "가을(Kim, 2005)" 문단을 1회 읽은 후, 첫 번째 문장인 "우리나라 의 가을은 참으로 아름답다.”에 해당하는 구간을 편집하였다.

\section{자료분석}

음향학적 분석

편집한 음성 자료는 KayPENTAX사의 $\mathrm{ADSV}^{\mathrm{TM}}$ (Analysis of Dysphonia in Speech and Voice)를 사용하여 캡스트럼 분석을 실 시하였다. 캡스트럼 분석 시(Apply Automatic Data Selection) 기능 을 활용하여 분석 프로그램이 자동으로 설정하는 구간을 분석하 였다. 표본추출률은 $22,050 \mathrm{~Hz}$, 양자화는 $16 \mathrm{bit}$ 로 설정하였다. 캡 스트럼 분석을 통해 분석한 음향학적 변수는 $\mathrm{CPP}, \mathrm{L} / \mathrm{H}$ ratio, mean $\mathrm{CPP} \mathrm{F}_{0}$ 이다.

\section{청지각적 분석}

경력 10 년 이상의 음성언어재활사 1 명, 음성장애 전공 언어치료 학과 교수 1 명 및 본 논문의 제 1 저자가 모음연장발성과 연속발화에 서 GRBAS 척도를 사용하여 5 개의 항목 $(\mathrm{G}, \mathrm{R}, \mathrm{B}, \mathrm{A}, \mathrm{S})$ 을 개별적으

Table 1. Subjects information ( $N=92)$

\begin{tabular}{|c|c|c|c|c|}
\hline \multirow{2}{*}{ Group } & \multirow{2}{*}{ Grade } & \multirow{2}{*}{ Diagnosis (N) } & \multicolumn{2}{|c|}{ Number of samples } \\
\hline & & & $\mathrm{N}$ & Total (M/F) \\
\hline \multirow[t]{3}{*}{ Hyper } & G1 & Contact granuloma (2), laryngitis (2), vocal nodule (3), vocal polyp (2), ADSD (1), vocal fatigue (1) & 11 & $46(14 / 32)$ \\
\hline & G2 & Contact granuloma (2), laryngitis (1), vocal nodule (4), vocal polyp(4), Reinke's edema (1), ADSD (5) & 17 & \\
\hline & G3 & Laryngitis (2), vocal nodule (1), vocal polyp (4), ADSD (8), Reinke's edema (3) & 18 & \\
\hline \multirow[t]{3}{*}{ Нуро } & G1 & PD (1), presbylaryngis (1), sulcus vocalis (2), vocal atrophy (1), vocal bowing (1), VCP (4), thyroid cartilage Fx. (1) & 11 & $46(25 / 21)$ \\
\hline & G2 & VCP (10), vocal atrophy (1), presbylaryngis (1), sulcus vocalis (4), vocal scarring (1) & 17 & \\
\hline & G3 & VCP (13), sulcus vocalis (5) & 18 & \\
\hline
\end{tabular}

Hyper = hyperfunctional voice disorders; Hypo=hypofunctional voice disorders; $\mathrm{M}=$ male; $\mathrm{F}=$ female; $\mathrm{G}=$ overall grade in $\mathrm{GRBAS}$ scale; $\mathrm{N}=$ number of subjects; $\mathrm{ADSD}=$ adductor spasmodic dysphonia; $\mathrm{VCP}=$ vocal fold paralysis; $\mathrm{PD}=$ Parkinson's disease; Fx. = fracture. 
로 평가하였다. 평가 시 두 점수 사이에서 판단이 모호할 경우 평가 치의 오류를 최소화하기 위해 0.5 점을 부과하여 7점 척도로 평가하 였다. 세 명의 평가자 간 평가결과가 불일치할 경우에는 재평가 후 합의된 평가결과를 사용하였다. 단, 집단 내에서 중증도를 분류하 기 위해서는 $\mathrm{G}$ 척도에서 소수점 이하는 반올림하여 0점(정상)에서 3점(심함)까지 4점 척도로 분류하였다.

\section{통계처리}

음성장애 분류에 따른 집단(Hyper vs. Hypo)과 발화과제 유형 (모음연장발성 vs. 연속발화)에 따른 음향학적(캡스트럼 분석) 및 청지각적(GRBAS 척도) 음성평가의 차이가 있는지를 살펴보기 위 해 집단 간 변수는 집단으로 하고, 집단 내 변수는 발화과제 유형으 로 하며, 두 집단 간의 성별 분포가 동일하지 않은 점을 고려하여 성 별을 공변량으로 하는 이요인 반복측정분산분석(repeated measures two-way ANOVA)을 실시하였다. 각 집단 내 GRBAS 척도와 캡스트럼 변수 간의 상관성을 알아보기 위해 피어슨 상관분석

Table 2. Comparisons of cepstral analysis by group and task

\begin{tabular}{|c|c|c|}
\hline Source & $F$ & $p$ \\
\hline \multicolumn{3}{|l|}{ CPP } \\
\hline Task & 37.084 & $<.001$ \\
\hline Group & 3.119 & .081 \\
\hline Task×Group & 7.233 & .009 \\
\hline \multicolumn{3}{|l|}{ Mean CPP Fo } \\
\hline Task & 36.199 & $<.001$ \\
\hline Group & 12.063 & .001 \\
\hline Task×Group & 11.51 & .001 \\
\hline \multicolumn{3}{|l|}{ L/H ratio } \\
\hline Task & 0.011 & .918 \\
\hline Group & 1.114 & .294 \\
\hline Task×Group & 2.72 & .103 \\
\hline
\end{tabular}

$\mathrm{CPP}=$ cepstral peak prominence; $\mathrm{F}_{0}=$ fundamental frequency; $\mathrm{L} / \mathrm{H}$ ratio $=$ ratio of low to high-frequency spectral energies; Task=sustained vowel and connected speech; Group = hyper- and hypo-functional voice disorders
(Pearson correlation analysis)을 실시하였다. 통계프로그램은 SPSS 20.0TM을 사용하였고, 유의수준은 .05로 하였다.

\section{연구결과}

\section{집단 간 발화과제 유형에 따른 음향학적 음성평가 차이}

집단 간 발화과제 유형에 따른 음향학적 음성평가의 차이를 살 펴보면(Table 2), 집단과 발화과제 유형 간에 유의한 상호작용이 나 타난 음향학적 변수는 $\mathrm{CPP}(F=7.233, p=.009)$ 와 mean CPP $\mathrm{F}_{0}$ $(F=11.510, p=.001)$ 였다. 집단에 따른 차이는 mean CPP $\mathrm{F}_{0}$ 에서 유 의하게 나타났고 $(F=12.063, p=.001)$, 발화과제 유형에 따라서는 $\mathrm{CPP}(F=37.084, p<.001)$ 와 mean $\mathrm{CPP} \mathrm{F}_{0}(F=36.199, p<.001)$ 에 서 유의한 차이가 있었다. L/H ratio는 집단이나 발화과제 유형에 따른 차이가 나타나지 않았다.

Table 3과 Figure 1에 따르면, $\mathrm{CPP}$ 는 모음연장발성에서 Hyper 집 단이 Hypo 집단에 비해 평균값이 높았으나 연속발화에서는 두 집 단 간의 평균값의 차이가 크지 않은 반면, mean $\mathrm{CPP} \mathrm{F}_{0}$ 는 모음연 장발성과 연속발화 모두에서 Hyper 집단이 Hypo 집단에 비해 평 균값이 낮은 경향을 보였다. 또한 $\mathrm{CPP}$ 는 모음연장발성이 연속발화 에 비해 높았으나 mean $\mathrm{CPP} \mathrm{F}_{0}$ 는 연속발화가 모음연장발성에 비

Table 3. Descriptive statistics of cepstral analysis by group and task

\begin{tabular}{llcc}
\hline Parameter & Group & Sustained vowel & Connected speech \\
\hline CPP & Hyper & $10.01(3.52)$ & $5.51(1.95)$ \\
& Hypo & $8.37(3.88)$ & $5.10(2.39)$ \\
Mean CPP Fo & Hyper & $150.61(38.69)$ & $179.98(30.45)$ \\
& Hypo & $177.36(56.63)$ & $191.37(40.68)$ \\
L/H ratio & Hyper & $28.30(5.29)$ & $28.21(4.52)$ \\
& Hypo & $30.21(6.78)$ & $28.79(5.02)$ \\
\hline
\end{tabular}

Values are presented as mean (SD).

$\mathrm{CPP}=$ cepstral peak prominence; $\mathrm{F}_{0}=$ fundamental frequency; $\mathrm{L} / \mathrm{H}$ ratio $=$ ratio of low to high-frequency spectral energies; Hyper=hyperfunctional voice disorders; Hypo = hypofunctional voice disorders; SD = standard deviation.
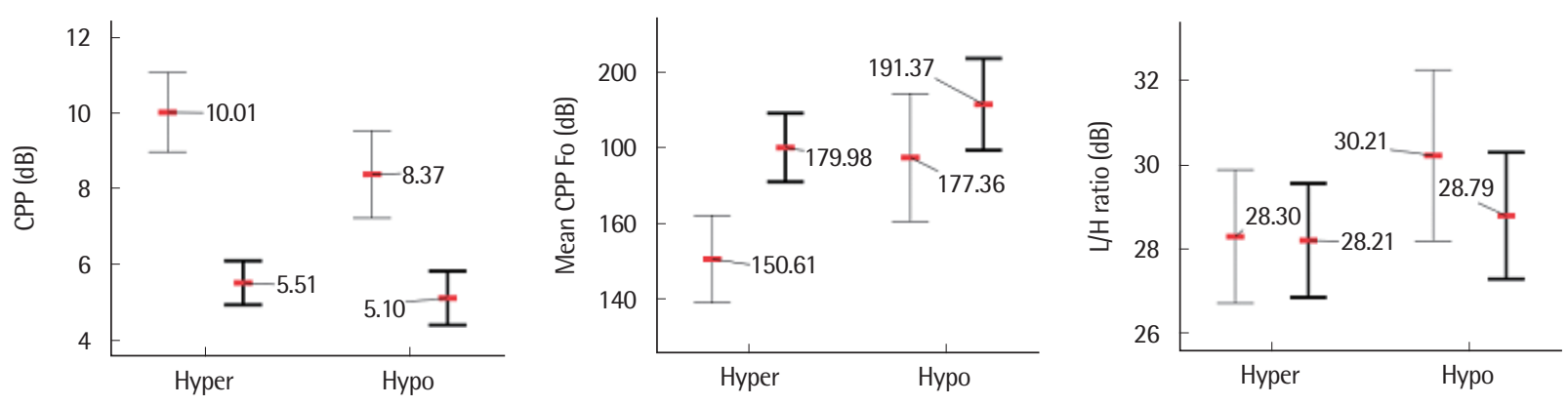

Figure 1. Cepstral analysis by task within each group. $C P P=$ cepstral peak prominence; $F_{0}=$ fundamental frequency; $L / H$ ratio= ratio of low to high-frequency spectral energies; Hyper=hyperfunctional voice disorders; Hypo=hypofunctional voice disorders; I= sustained vowel; $I$ = connected speech. 
Eun-Jung Lee, et al. • Voice evaluation in Sustained Vowel and Connected Speech by Glottal Closure Pattern

해 유의하게 높았다.

\section{집단 간 발화과제 유형에 따른 청지각적 음성평가 차이}

집단 간 발화과제 유형에 따른 청지각적 음성평가의 차이를 살펴 보면(Table 4), 모든 청지각적 척도에서 집단과 발화과제 유형 간의 유의한 상호작용은 나타나지 않았다. 집단에 따른 차이는 $\mathrm{B}$ 척도 $(F=12.323, p=.001)$ 와 $\mathrm{A}$ 척도 $(F=13.159, p<.001)$ 에서 유의하게

Table 4. Comparisons of GRBAS scale by group and task

\begin{tabular}{lccc}
\hline Parameter & Source & $F$ & $p$ \\
\hline $\mathrm{G}$ & Task & 11.019 & .001 \\
& Group & 0.112 & .739 \\
& Task $\times$ Group & 0.678 & .412 \\
$\mathrm{R}$ & Task & 8.239 & .005 \\
& Group & 0.919 & .340 \\
& Task $\times$ Group & 0.079 & .779 \\
$\mathrm{~B}$ & Task & 4.688 & .033 \\
& Group & 12.323 & .001 \\
& Task $\times$ Group & 1.419 & .237 \\
$\mathrm{~A}$ & Task & 10.878 & .001 \\
& Group & 13.159 & $<.001$ \\
& Task $\times$ Group & 0.032 & .859 \\
$\mathrm{~S}$ & Task & 5.455 & .022 \\
& Group & 3.104 & .082 \\
& Task $\times$ Group & 2.739 & .101 \\
\hline
\end{tabular}

$R=$ rough; $B=$ breathy; $A=$ asthenic; $S=$ strained; Task=sustained vowel and connected speech; Group=hyper- and hypo-functional voice disorders .
나타났고, 발화과제 유형에 따라서는 $\mathrm{G}$ 척도 $(F=11.019, p=.001), \mathrm{R}$ 척도 $(F=8.239, p=.005), \mathrm{B}$ 척도 $(F=4.688, p=.033), \mathrm{A}$ 척도 $(F=$ $10.878, p=.001), S$ 척도 $(F=5.455, p=.022)$ 모두에서 유의한 차이 가 있었다.

Table 5 와 Figure 2를 보면, $\mathrm{G}$ 척도, R척도, $\mathrm{S}$ 척도의 평균값은 $\mathrm{Hy}-$ per 집단이 Hypo 집단에 비해 높은 반면, $\mathrm{B}$ 척도와 $\mathrm{A}$ 척도의 평균값 은 Hyper 집단이 Hypo 집단에 비해 낮은 경향을 보였다. 또한 모든 청지각적 척도에서 연속발화가 모음연장발성에 비해 평균값이 높 았다.

Table 5. Descriptive statistics of GRBAS scale by group and task

\begin{tabular}{llcr}
\hline Parameter & Group & Sustained vowel & Connected speech \\
\hline G & Hyper & $1.92(.70)$ & $2.01(.73)$ \\
& Hypo & $1.91(.76)$ & $1.99(.84)$ \\
R & Hyper & $1.82(.74)$ & $1.91(.76)$ \\
& Hypo & $1.66(.76)$ & $1.85(.79)$ \\
B & Hyper & $1.08(.66)$ & $1.16(.71)$ \\
& Hypo & $1.70(.73)$ & $1.71(.92)$ \\
A & Hyper & $.21(.40)$ & $.25(.50)$ \\
& Hypo & $.55(.66)$ & $.68(.72)$ \\
S & Hyper & $1.60(.79)$ & $1.65(.84)$ \\
& Hypo & $1.24(.71)$ & $1.51(.81)$ \\
\hline
\end{tabular}

Values are presented as mean (SD).

$\mathrm{G}=$ overall grade; $\mathrm{R}=$ rough; $\mathrm{B}=$ breathy; $\mathrm{A}=$ asthenic; $\mathrm{S}=$ strained; Hyper= hyperfunctional voice disorders; Hypo=hypofunctional voice disorders; $S D=$ standard deviation.

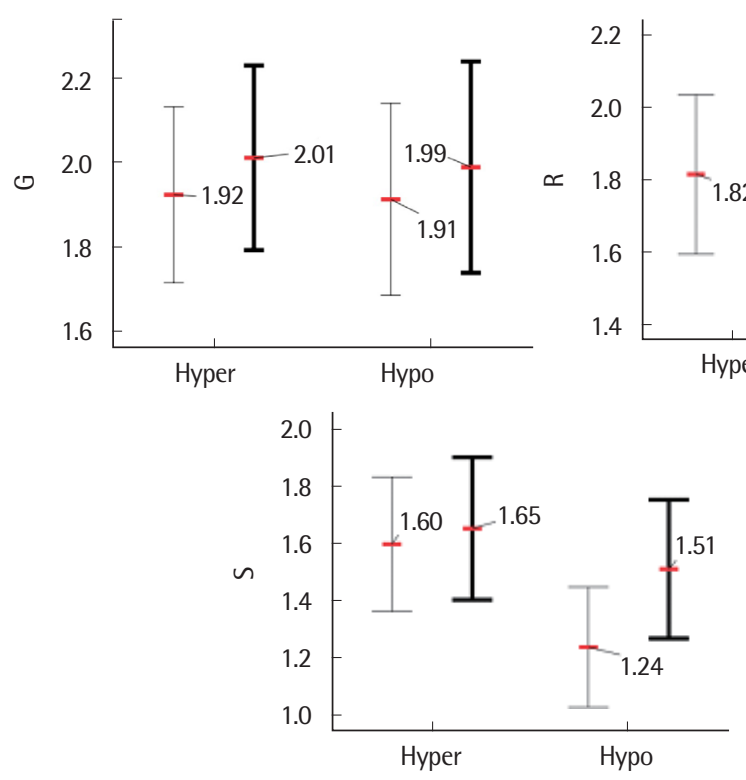

Figure 2. GRBAS scale by task within each group. $G=$ overall grade; $R=$ rough; $B=$ breathy; $A=$ asthenic; $S=$ strained; Hyper=hyper-functional voice disorders; Hypo = hypofunctional voice disorders; $\mathrm{I}=$ sustained vowel; $\mathrm{I}=$ connected speech. 
Table 6. Correlation among GRBAS scale and cepstral analysis in excessive vocal fold closure

\begin{tabular}{|c|c|c|c|c|c|c|c|c|c|c|}
\hline \multirow{2}{*}{ Parameter } & \multicolumn{5}{|c|}{ Sustained vowel } & \multicolumn{5}{|c|}{ Connected speech } \\
\hline & G & $\mathrm{R}$ & B & A & $S$ & G & $\mathrm{R}$ & B & A & $S$ \\
\hline \multicolumn{11}{|l|}{ Sustained vowel } \\
\hline СPP & $-.71^{* *}$ & $-.63^{* *}$ & $-.55^{* *}$ & -0.18 & $-.60^{* *}$ & $-.51^{* *}$ & $-.45^{* *}$ & $-.45^{* *}$ & $-.32^{*}$ & $-.59^{* *}$ \\
\hline $\mathrm{L} / \mathrm{H}$ ratio & $-.55^{* *}$ & $-.54^{* *}$ & $-.46^{* *}$ & -0.14 & $-.58^{* *}$ & $-.43^{* *}$ & $-.39 * *$ & $-.38^{* *}$ & -0.22 & $-.50^{* *}$ \\
\hline Mean CPP Fo & 0.24 & 0.19 & 0.21 & 0.12 & 0.18 & 0.02 & -0.07 & 0.03 & -0.04 & 0.11 \\
\hline \multicolumn{11}{|c|}{ Connected speech } \\
\hline CPP & $-75^{* *}$ & $-.70^{* *}$ & $-.44^{* *}$ & 0.03 & $-.79^{* *}$ & $-.81^{* *}$ & $-.77^{* *}$ & $-.59^{* *}$ & -0.18 & $-.85^{* *}$ \\
\hline $\mathrm{L} / \mathrm{H}$ ratio & $-58^{* *}$ & $-.55^{* *}$ & $-.42^{* *}$ & -0.03 & $-.69^{* *}$ & $-.57^{* *}$ & $-.52^{* *}$ & $-.41^{* *}$ & -0.15 & $-.66^{* *}$ \\
\hline Mean $\mathrm{CPP}_{0}$ & 0.22 & 0.15 & 0.24 & 0.16 & 0.24 & 0.18 & 0.09 & 0.17 & -0.05 & 0.26 \\
\hline
\end{tabular}

$\mathrm{G}=$ overall grade; $\mathrm{R}=$ rough; $\mathrm{B}=$ breathy; $\mathrm{A}=$ asthenic; $\mathrm{S}=$ strained; $\mathrm{CPP}=$ cepstral peak prominence; $\mathrm{F}_{0}=$ fundamental frequency; $\mathrm{L} / \mathrm{H}$ ratio= ratio of low to high-frequency spectral energies.

${ }^{*} p<.05,{ }^{* *} p<.01$.

Table 7. Correlation among GRBAS scale and cepstral analysis in insufficient vocal fold closure

\begin{tabular}{|c|c|c|c|c|c|c|c|c|c|c|}
\hline \multirow{2}{*}{ Parameter } & \multicolumn{5}{|c|}{ Sustained vowel } & \multicolumn{5}{|c|}{ Connected speech } \\
\hline & $G$ & $\mathrm{R}$ & B & A & $S$ & G & $\mathrm{R}$ & B & A & $S$ \\
\hline \multicolumn{11}{|l|}{ Sustained vowel } \\
\hline CPP & $-.78^{* *}$ & $-.60^{* *}$ & $-.80^{* *}$ & $-.46^{* *}$ & $-.63^{* *}$ & $-.67^{* *}$ & $-.62^{* *}$ & $-.76^{* *}$ & $-.59 * *$ & $-.66^{* *}$ \\
\hline $\mathrm{L} / \mathrm{H}$ ratio & $-.54^{* *}$ & $-.45^{* *}$ & $-.61^{* *}$ & -0.26 & $-.55^{* *}$ & $-.45^{* *}$ & $-.44^{* *}$ & $-.58^{* *}$ & $-.42^{* *}$ & $-.48^{* *}$ \\
\hline Mean $\mathrm{CPP} \mathrm{F}_{0}$ & 0.22 & 0.06 & $.33^{*}$ & $.38^{* *}$ & 0.15 & $.33^{*}$ & 0.29 & $.40^{* *}$ & $.40^{* *}$ & $.36^{*}$ \\
\hline \multicolumn{11}{|c|}{ Connected speech } \\
\hline СРP & $-.77^{* *}$ & $-.61^{* *}$ & $-.75^{* *}$ & $-.42^{* *}$ & $-.56^{* *}$ & $-.82^{* *}$ & $-.75^{* *}$ & $-.79^{* *}$ & $-.59^{* *}$ & $-.80^{* *}$ \\
\hline L/H ratio & $-.58^{* *}$ & $-.40^{* *}$ & $-.65^{* *}$ & -0.26 & $-.44^{* *}$ & $-.60^{* *}$ & $-.56^{* *}$ & $-.69^{* *}$ & $-.47^{* *}$ & $-.59^{* *}$ \\
\hline Mean CPP Fo & $.36^{*}$ & 0.17 & $.42^{* *}$ & $.39 * *$ & 0.2 & $.37^{*}$ & $.31^{*}$ & $.44^{* *}$ & $.50^{* *}$ & $.38^{* *}$ \\
\hline
\end{tabular}

$G=$ overall grade; $R=$ rough; $B=$ breathy; $A=$ asthenic; $S=$ strained; $C P P=$ cepstral peak prominence; $F_{0}=$ fundamental frequency; $L / H$ ratio= ratio of low to high-frequency spectral energies.

${ }^{*} p<.05,{ }^{* *} p<.01$.

\section{집단 내 음향학적 및 청지각적 변수 간의 상관관계}

\section{Hyper 집단의 음향학적 및 청지각적 변수 간 상관관계}

Hyper 집단에서 발화과제 유형별 음향학적 및 청지각적 변수 간 의 상관성을 살펴본 결과(Table 6), 두 발화과제 유형 모두에서 $\mathrm{A}$ 척 도를 제외한 $\mathrm{GRBS}$ 척도와 $\mathrm{CPP}$ 및 $\mathrm{L} / \mathrm{H}$ ratio 간에 유의한 중간 이 상의 부적 상관관계( $r=-.38$ - .85)를 보였다. $\mathrm{A}$ 척도의 경우 모음연 장발성의 $\mathrm{CPP}$ 와 연속발화의 $\mathrm{A}$ 척도 간에만 유의하게 낮은 부적 상 관관계 $(r=-.32)$ 를 보였고, 두 발화과제 유형의 다른 모든 캡스트럼 분석 결과와는 유의한 상관성이 없었다. 또한 두 발화과제 유형 모 두 GRBAS 척도와 mean $\mathrm{CPP} \mathrm{F}_{0}$ 간에 유의한 상관관계가 없었다.

Hypo 집단의 음향학적 및 청지각적 변수 간 상관관계

Hypo 집단에서 발화과제 유형별 음향학적 및 청지각적 변수 간 의 상관성을 살펴본 결과(Table 7), GRBAS 척도는 두 발화과제 유 형 모두의 $\mathrm{CPP}$ 와 중간 이상의 유의하게 높은 부적 상관관계를 보
였고( $r=-.42 \sim .82)$, GRBAS 척도와 $\mathrm{L} / \mathrm{H}$ ratio 간에는 두 발화과제 유형의 $\mathrm{A}$ 척도를 제외하고 모두 중간 정도의 유의한 부적 상관관계 를 보였다 $(r=-.40 \sim-69)$. GRBAS 척도와 mean $\mathrm{CPP} \mathrm{F}_{0}$ 간의 상관성 은 모음연장발성의 mean $\mathrm{CPP} \mathrm{F}_{0}$ 가 모음연장발성의 $\mathrm{B}$ 척도 $(r=.33)$ 와 $\mathrm{A}$ 척도 $(r=.38)$, 연속발화의 $\mathrm{R}$ 척도를 제외한 $\mathrm{G}, \mathrm{B}, \mathrm{A}, \mathrm{S}$ 척도 $(r=.33-40)$ 와 중간 정도의 유의한 정적 상관관계를 보였고, 연속발 화의 mean $\mathrm{CPP} \mathrm{F}_{0}$ 는 모음연장발성의 R척도와 $\mathrm{S}$ 척도를 제외한 $\mathrm{G}$, $\mathrm{B}, \mathrm{A}$ 척도와 연속발화의 모든 GRBAS 척도 간에 중간 정도의 유의 한 정적 상관관계를 보였다 $(r=.31-.50)$.

\section{논의 및 결론}

본 연구는 후두의 기질적 또는 신경학적 이상 유무에 상관없이 음성장애를 발성 시의 성대접촉 양상과 후두긴장 여부에 따라 $\mathrm{Hy}-$ per 집단과 Hypo 집단으로 분류한 후, 두 집단 간 모음연장발성과 
Eun-Jung Lee, et al. • Voice evaluation in Sustained Vowel and Connected Speech by Glottal Closure Pattern COMMUNICATION SCIINCES \& DISORDERS

연속발화 시의 음향학적 및 청지각적 평가의 차이를 살펴보고, 각 집단 내에서의 음향학적 및 청지각적 측정 변수들 간의 상관관계 를 알아보고자 하였다. 즉 성대접촉 양상에 따른 음향학적 및 청지 각적 분석 결과에 차이가 있는지를 살펴보고, 임상에서 음성평가 시 주로 사용되는 모음연장발성 과제와 연속발화 과제에 따라서 음향학적 및 청지각적 분석 결과가 다르게 나타나는지를 분석하고 자 하였다. 이를 통해 음성장애를 일반적으로 병인적 원인에 따라 분류하여 기능적, 기질적, 신경학적 음성장애로 구분하는 것 외에 음성치료의 목표를 설정하는데 있어 발성 시의 성대접촉 양상에 따른 특성으로 음성장애를 분류하는 것이 적합한지를 음성평가를 통해 파악하고자 하는데 주된 목적이 있다.

우선 두 집단 간 발화과제 유형에 따른 음향학적 평가의 차이를 살펴보면, 조화음의 정도를 나타내는 $\mathrm{CPP}$ 는 두 집단 모두 모음연 장발성에서 높게 나타났는데, 이는 선행연구에서도 지적한 바와 같 이 모음연장발성이 유성음으로만 이루어져 있어 조화음 정도가 높 고, 연속발화는 다양한 무성음과 유성음이 혼재되어 있어 주기성 에 제한을 받을 뿐 아니라 주파수나 진폭의 변동, 음성일탈과 같은 특성을 잘 포함하고 있기 때문이다(Heman-Ackah, Michael, \& Goding, 2002; Shim et al., 2016). 이에 CPP를 통한 음질 평가 시 모 음연장발성을 단독으로 사용할 경우 실제보다 좋은 음질로 평가 될 가능성이 있다. 두 집단 간 $\mathrm{CPP}$ 의 차이는 통계적으로 유의하지 는 않았지만 Hyper 집단이 Hypo 집단에 비해 다소 높게 나타나 발 성 시 후두의 긴장성을 증가시켜 성대를 과다하게 접촉한 경우보다 성대가 불완전하게 접촉하는 기식성이 특징인 경우에서 음질이 더 저하될 수 있음을 보여준다.

Mean $\mathrm{CPP} \mathrm{F}_{0}$ 는 두 집단 모두 모음연장발성 보다 연속발화에서, 그리고 두 발화과제 유형 모두 Hyper 집단에 비해 Hypo 집단에서 더 높게 나타났다. Mean $\mathrm{CPP} \mathrm{F}_{0}$ 는 음성신호에서 가장 강한 조화음 에너지를 갖는 주파수로 기본주파수와 관련이 높으며 후두의 긴장 이 증가할수록 높아지고, 기식성이 높아지면 낮아지는 경향이 있 다(Hammarberg et al., 1980; Hillenbrand et al., 1994; Lowell et al., 2012; Lowell, Colton, Kelley, \& Mizia, 2013; Seo \& Seong, 2013; Shim et al., 2016). 연속발화에 비해 모음연장발성은 비교적 후두의 긴장을 감소한 상태에서 일정하게 산출하는 반면 연속발화는 억양 이나 강세로 인해 후두의 긴장도가 높고 변화가 클 수 있기 때문에 Mean CPP F 는 연속발화상에서 더 높게 나타난 것으로 보인다. 또 한 본 연구의 Hyper 집단은 성대의 질량이 증가하여 기본주파수가 낮아지는 음성장애가 많은 반면, Hypo 집단은 발성 시 불완전 성 대접촉의 보상작용으로 인해 성대의 긴장성이 증가함으로써 기본 주파수가 상승하여 Mean CPP Fo가 더 높게 나타난 것으로 보인다.
즉, mean $\mathrm{CPP} \mathrm{F}_{0}$ 는 연속발화 상에서 긴장성과 기식성을 판단하는 데에는 유용하지만 성대접촉 양상으로 구분되는 Hyper 집단과 Hypo 집단 간의 긴장성과 기식성을 변별하는 데에는 다소 어려움 이 있다고 볼수 있다.

$\mathrm{L} / \mathrm{H}$ ratio는 스펙트럼 에너지의 저주파수와 고주파수의 에너지 비율을 나타내는 것으로 음질문제 및 기식성을 변별하는데 사용 되는데, 일반적으로 기식성은 고주파 음역대의 많은 소음으로 인 해 에너지가 낮아 $\mathrm{L} / \mathrm{H}$ ratio가 높게 나타나고, 긴장성은 고주파 음 역대에서 에너지가 높아 L/H ratio가 낮다(Nordstrom, 2008; Seo \& Seong, 2013). 본 연구에서는 $\mathrm{L} / \mathrm{H}$ ratio가 집단 간에도 그리고 발 화과제 유형 간에도 유의한 차이가 없었다. 이는 다양한 기능적, 기 질적 원인으로 인해 나타나는 긴장성이 $\mathrm{L} / \mathrm{H}$ ratio를 통해서는 정상 화자와의 차이를 변별되지 못하였고(Lowell et al., 2012), 긴장성과 기식성이 섞여 있는 마비말장애 화자에서도 두 음질 특성이 중화되 어 정상화자의 $\mathrm{L} / \mathrm{H}$ ratio와 차이가 없었던 결과(Seo \& Seong, 2013)와 마찬가지로 Hyper 집단에서 관찰되는 긴장성과 Hypo 집 단에서 보상작용에 의해 나타나는 긴장성의 차이는 $\mathrm{L} / \mathrm{H}$ ratio로 변 별하기 어려움을 알 수 있다. 이와는 반대의 결과를 보인 Watts와 Awan (2011)의 연구에서는 일측성 성대마비, 파킨슨병 및 성대구 증의 성대폐쇄부전을 보이는 Hypo 집단이 정상화자에 비해 $\mathrm{L} / \mathrm{H}$ ratio가 유의하게 낮았는데, 이는 정상화자에 비해 Hypo 집단의 측 정치의 변이가 커서 나타난 차이라고 설명하였다. 다만, 모음연장발 성에서 Hyper 집단에 비해 Hypo 집단의 $\mathrm{L} / \mathrm{H}$ ratio 평균값이 다소 높게 나타나 유성음과 무성음 등의 다양한 음질요인이 포함된 연 속발화에 비해 음질요인의 변동이 적은 모음연장발성에서 Hypo 집단의 특성인 기식성이 더 잘 반영됨을 알 수 있다.

성대접촉 양상에 따라 구분된 두 집단 간 모음연장발성과 연속 발화의 음향학적 특성을 비교한 결과를 종합해 볼 때, Hyper 집단 에서 $\mathrm{CPP}$ 가 높게 나타난 반면, mean $\mathrm{CPP} \mathrm{F}_{0}$ 는 Hypo 집단에서 높 게 나타났다. 이는 긴장성이 주된 특징인 Hyper 집단에 비해 성대 폐쇄부전으로 기식성이 주로 나타나는 Hypo 집단이 보상전략에 의한 과다기능적 긴장성이 함께 동반되어 신호의 비주기성을 증가 시킨다고 볼 수 있다. 또한 발화과제 유형 중 연속발화에서 음성장 애의 음향학적 특성이 더 잘 나타났는데, 이는 연속발화에서 실제 적이고 일반화된 음성평가를 실시할 수 있다는 선행연구 결과와도 일치하며(Parsa \& Jamieson, 2001; Roy et al., 2005; Yui et al., 2000), 음향학적 음성평가를 실시할 때 모음연장발성 과제와 더불어 연속 발화도 함께 실시해야함을 시사한다.

다음으로 집단 간 발화과제 유형에 따른 청지각적 음성평가의 차이를 살펴본 결과, 모든 GRBAS 척도에서 모음연장발성에 비해 
연속발화에서 유의하게 높게 나타났다. 이는 연속발화가 주파수 및 진폭의 변동이나음성일탈과 같은 특성을 포함하고 있어 실질적 인 음성평가에 유용하며(Parsa \& Jamieson, 2001), 모음연장발성보 다 연속발화 상에서 음질의 나쁜 정도가 더 잘 드러난다는 선행연 구 결과와도 일치한다(Sapienza, Walton, \& Murry, 2000; Shim, 2016; Yui et al., 2000). 또한 B척도와 A척도가 Hyper 집단에 비해 Hypo 집단에서 유의하게 높게 나타나 Hypo 집단에서 기식성과 약 한 음성이 특징적으로 나타난다는 선행연구와 일치하는 결과를 보 였다(Ramig \& Verdolini, 1998; Shin et al., 2011). 한편 R척도와 S척 도는 Hypo 집단에 비해 Hyper 집단에서 높게 나타났으나 그 차이 는 유의하지 않았다. 선행연구에 의하면, Hyper 음성장애와 같이 발성 시 성대를 과도하게 접촉하고 후두의 긴장성이 높아진 경우에 지속적으로 긴장하고 쥐어짜는 듯한음성이 산출되지만, 성대마비 와 같은 성대 폐쇄부전이 있는 경우 보상적 발성으로 기식성과 더 불어 긴장성 및 거친 음성이 동반될 수 있다(Lowell et al., 2012; Seo \& Seong, 2013). 본 연구에 포함된 대상자 중에서 R척도와 $S$ 척도에 서 2점(moderate) 이상인 경우가 Hyper 집단은 R척도 30명, $\mathrm{S}$ 척도 22 명, Hypo 집단은 R척도 25 명, $\mathrm{S}$ 척도 20 명으로 두 집단의 R척도 와 $S$ 척도에 해당하는 대상자의 비율이 유사하였다. Hyper 집단의 특징적 음성인 R척도와 $S$ 척도는 Hypo 집단에서도 불완전 성대접 촉에 대한 보상작용으로 증가하는 경우가 많아 $\mathrm{R}$ 척도와 $\mathrm{S}$ 척도로 Hyper 집단과 Hypo 집단을 구분하는 것이 용이하지 않음을 알 수 있다. 다시 말해 거친 음성(R)과 긴장성(S)은 성대접촉이 과도하게 이루어졌을 때 특징적으로 나타나지만 성대가 불완전하게 접촉하 였을 때에도 과다기능적 보상전략으로 인해 긴장성이 증가하는 경 우가 많다는 것이다.

두 집단의 모음연장발성과 연속발화에서 청지각적 음성평가를 비교한 결과를 종합해 볼 때, 기식성(B)과 약한 음성(A)은 Hypo 집 단이 Hyper 집단 보다 높은 반면 거친 음성(R)과 긴장성(S)은 두 집 단 간에 차이가 없었고, 두 집단 모두 GRBAS 척도가 모음연장 발 성에 비해 연속발화에서 높게 나타나 발화과제 유형에 따라 차이 가 있음을 알수 있다.

마지막으로 각 집단 내에서 음향학적 및 청지각적 측정 변수들 간의 상관관계를 살펴본 결과, 모든 음성장애 집단 및 발화과제 유 형에서 $\mathrm{CPP}$ 가 높을수록 GRBAS 척도들은 낮아지는 부적 상관관 계가 나타나 음질의 정도가 좋다고 평가되었다. 이는 음질에 심각 한 문제가 있을 경우에 모음연장발성이나 연속발화 상에서의 CPP 가 유의하게 낮아진다는 선행연구 결과와 일치하며(Kumar, Bhat, \& Prasad, 2009; Watts \& Awan, 2011), CPP와 청지각적 평가 간에 높은 상관관계가 있음을 보여준다. 즉, 조화음의 정도가 높을수록
청지각적으로도 좋은 음질로 평가된다. 다만, Hypo 집단에서의 모 음연장발성 $\mathrm{CPP}$ 와 모음연장발성 $\mathrm{A}$ 척도 간에 유의한 상관관계가 나타나지 않았는데, 이는 $\mathrm{A}$ 척도의 음성적 특징이 명확한 성질을 가 지고 있지는 않기 때문으로 보인다(Wolfe, Cornell, \& Fitch, 1995). Mean $\mathrm{CPP} \mathrm{F}_{0}$ 는 Hyper 집단에서는 두 발화과제 유형 모두에서 청 지각적 평가와 유의한 상관관계가 없었던 반면, Hypo 집단에서는 두 발화과제 유형 모두에서 $\mathrm{B}$ 척도 및 $\mathrm{A}$ 척도와의 상관관계가 높아 mean $\mathrm{CPP} \mathrm{F}_{0}$ 가 청지각적으로 평가되는 기식성과 높은 상관관계 를 보인다고 할 수 있다. 이는 mean $\mathrm{CPP} \mathrm{F}_{0}$ 와 긴장성 및 기식성과의 상관성에 관한 선행연구와 맥락을 같이 한다(Seo \& Seong, 2013). 또한 두 집단과 두 발화과제 유형 모두에서 $\mathrm{L} / \mathrm{H}$ ratio가 높을수록 GRBAS 척도들 간의 부적 상관관계가 나타났는데, 청지각적으로 음질이 좋게 평가될수록 저주파수 영역대의 에너지가 많고 고주파 수 영역대의 소음성 에너지가 적기 때문에 $\mathrm{L} / \mathrm{H}$ ratio와 청지각적 평 가 간에 높은 상관관계가 있음을 의미한다. 즉, 고주파 영역의 소음 성 에너지가 적을수록 청지각적으로 좋은 음질로 평가됨을 알 수 있다. 다만, $\mathrm{A}$ 척도의 명확하지 않은 음성적 특징으로 인해(Wolfe et al., 1995), Hypo 집단에서 모음연장발성의 L/H ratio와 A척도 간에 는 유의한 상관관계가 나타나지 않았다. 각 집단 내에서 두 음성평 가의 측정 변수 간의 상관분석을 종합해 보면, $\mathrm{CPP}$ 와 $\mathrm{L} / \mathrm{H}$ ratio가 높을수록 GRBAS 척도들은 낮아졌고 mean $\mathrm{CPP} \mathrm{F}_{0}$ 는 높아졌다. 이는 두 집단 모두에서 음향학적 음성평가와 청지각적 음성평가의 측정치 간에 높은 상관관계가 있음을 보여준다.

본 연구를 통해 성대접촉 양상과 후두의 긴장성 여부를 파악하 기 위해 음향학적 및 청지각적 음성평가를 실시할 때 모음연장발성 과 연속발화 과제를 함께 실시하는 것이 바람직하며, 이러한 평가 들은 성대폐쇄부전이 있는 Hypo 음성장애의 과다기능적 보상전 략을 감별하는데도 도움이 될 수 있음을 알 수 있다.

연구의 결과를 토대로 본 연구의 제한점과 후속 연구를 위한 제 언은 다음과 같다. 첫째, Hyper와 Hypo 집단 간의 음향학적 및 청 지각적 평가의 차이를 보다 명확하게 파악하기 위해서는 동일한음 성장애 질환 내에서 과다기능과 과소기능의 특성을 나타내는 집단 으로 구분하여 이들 간의 특성을 비교할 필요가 있다. 둘째, 일반적 으로 기본주파수는 성인 남성에 비해 성인 여성이 높다. 본 연구에 서는 성별을 공변량으로 하여 성별에 따른 영향력을 통제하고자 하였으나 향후 연구에서는 보다 정확한 결과를 얻기 위해 동일한 성별 내에서 성대접촉 양상과 후두 긴장성에 따른 음성장애 유형 간에 음향학적 및 청지각적 음성평가의 차이를 살펴볼 필요가 있 다. 셋째, 본 연구에서 적용한 음성장애 분류에 따라차별화된 음성 치료를 적용하였을 때의 효과성을 파악하지는 못하였다. 이에 향 
Eun-Jung Lee, et al. • Voice evaluation in Sustained Vowel and Connected Speech by Glottal Closure Pattern COMMUNICATION SCIINCES \& DISORDERS

후 연구에서는 성대접촉 양상 및 후두 긴장 상태에 따라 음성장애 를 분류한 후 이에 적합한 음성치료 전후의 변화를 살펴봄으로써 파악할 필요가 있다.

\section{REFERENCES}

Bonilha, H. S., White, L., Kuckhahn, K., Gerlach, T. T., \& Deliyski, D. D. (2012). Vocal fold mucus aggregation in persons with voice disorders. Journal of Communication Disorders, 45(4), 304-311.

Boone, D. R., McFarlane, S. C., Von Berg, S. L., \& Zraick, R. I. (2014). The voice and voice therapy (10th ed., J. Yoo, Y. Hwang, \& J. Han, Trans.). CA: Pearson.

Carding, P. N., Steen, I. N., Webb, A., Mackenzie, K., Deary, I. J., \& Wilson, J. A. (2004). The reliability and sensitivity to change of acoustic measures of voice quality. Clinical Otolaryngology Allied Sciences, 29(5), 538-544.

Carole, T. F. (2014). Voice disorder: scope of theory and practices (1st ed., S. T. Kim, H. Y. Pyo, \& S. B. Kwon, Trans.). Seoul: Pakhaksa.

Choi, S. H., \& Choi, C. H. (2014). The utility of perturbation, non-linear dynamic, and cepstrum measures of dysphonia according to signal typing. Phonetics and Speech Sciences, 6(3), 63-72.

Chung, S. M., Cho, Y. H., Hong, S. K., Byun, S. W., Kim, E. A., Son, J. Y., \& Park, A. K. (2002). The effect of voice therapy for functional voice disorder. The Korean Society of Laryngology, Phoniatrics and Logopedics, 13(2), 145-150.

Hammarberg, B., Fritzell, B., Gauffin, J., Sundberg, J., \& Wedin, L. (1980). Perceptual and acoustic correlates of abnormal voice qualities. Acta Otolaryngologica, 90(5-6), 441-451.

Heman-Ackah, Y. D., Michael, D. D., \& Goding, G. S. (2002). The relationship between cepstral peak prominence and selected parameters of dysphonia. Journal of Voice, 16(1), 20-27.

Hillenbrand, J., Cleveland, R., \& Erickson, R. (1994). Acoustic correlates of breathy vocal quality. Journal of Speech Hearing Research, 37(4), 769-778.

Hillenbrand, J., \& Houde, R. A. (1996). Acoustic correlates of breathy vocal quality: dysphonic voices and continuous speech. Journal of Speech and Hearing Research, 39(2), 311-321.

Jin, S. M. (2014). Pathophysiology of functional dysphonia. The Korean Society of Laryngology, Phoniatrics and Logopedics, 25(2), 75-78.

Kim, H. (2005). Assessment of dysarthria. Proceedings of 2005 Summer training seminar for language disorders, Korean Academy of Speech-Language Pathology and Audiology, 23-28.
Kim, J. S., Lee, D. W., Choi, C. H., \& Choi, S. H. (2017). Effects of laryngeal massage and semi-occluded vocal tract exercises for patients with hyperfunctional dysphonia. Communication Sciences and Disorders, 22(4), 806817.

Kim, S., Y, \& Lee, S. H. (2017). Differential diagnosis between neurogenic and functional dysphonia. The Korean Society of Laryngology, Phoniatrics and Logopedics, 28(2), 71-78.

Kumar, B. R., Bhat, J. S., \& Prasad, N. (2009). Cepstral analysis of voice in persons with vocal nodules. Journal of Voice, 24(6), 651-653.

Lee, M. S., \& Shin, H. J. (2010). The comparative study of auditory-perceptive evaluation and acoustic analyses on vowels and connected speech of dysphonia. Journal of Speech \& Hearing Disorders, 19(4), 17-37.

Lee, H. N., Yoo, J. Y., \& Park, J. H. (2019). Effect of online and offline voice therapy programs in patients with hyperfunctional voice disorder: a case study, Communication Sciences and Disorders, 24(3), 814-826.

Lee, R. H. (2019). A meta-analysis of the effectiveness of cepstral peak prominence in the assessment of voice disorder (Master's thesis). Chungnam National University, Daejeon, Korea.

Lee, S. J., Lee, K. Y., \& Choi, H. S. (2018). Clinical usefulness of voice recordings using a smartphone as a screening tool for voice disorders. Communication Sciences \& Disorders, 23(4), 1065-1077.

Lowell, S. Y., Colton, R. H., Kelley, R. T., \& Mizia, S. A. (2013). Predictive value and discriminant capacity of cepstral-and spectral-based measures during continuous speech. Journal of Voice, 27(4), 393-400.

Lowell, S. Y., Kelley, R. T., Awan, S. N., Colton, R. H., \& Chan, N. H. (2012). Spectral- and cepstral-based acoustic features of dysphonic, strained voice quality. Annals of Otology, Rhinology and Laryngology, 121(8), 539-548.

Nordstrom, K. I. (2008). Transforming high-effort voices into breathy voices using adaptive pre-emphasis linear prediction (Doctoral dissertation). University of Victoria, British Columbia, Canada.

Parsa, V., \& Jamieson, D. G. (2001). Acoustic discrimination of pathological voice: sustained vowels versus continuous speech. Journal of Speech, Language, and Hearing Research, 44(2), 327-339.

Ramig, L. O., \& Verdolini, K. (1998). Treatment efficacy: voice disorders. Journal of Speech, Language, and Hearing Research, 41(1), 101-116.

Roy, N., Gouse, M., Mauszycki, S. C., Merrill, M., \& Smith, M. E. (2005). Task specificity in adductor spasmodic dysphonia versus muscle tension dysphonia. The Laryngoscope, 115(2), 311-316.

Sapienza, C. M., Walton, S., \& Murry, T. (2000). Adductor spasmodic dysphonia and muscular tension dysphonia: acoustic analysis of sustained 
phonation and reding. Journal of Voice, 14(4), 502-520.

Seo, I., \& Seong, C. (2013). Voce quality of dysarthric speakers in connected speech. Phonetics and Speech Sciences, 5(4), 33-41.

Shim, H. J. (2016). Diagnostic effectiveness of cepstral and spectral analysis in understanding of muscle tension dysphonia and adductor spasmodic dysphonia (Doctoral dissertation). Hallym University, Chuncheon, Korea.

Shim, H. J., Jung, H., Lee, S. A., Choi, B. H., Heo, J. H., \& Ko, D. H. (2016) Cepstral and spectral analysis of voices with adductor spasmodic dysphonia. Phonetics and Speech Sciences, 8(2), 73-80.

Shim, S. Y., Kim, H. H., Kim, J. O., \& Shin, J. C. (2014). Difference in voice parameters of MDVP and Praat programs according to severity of voice disorders in vocal nodule. Phonetics and Speech Sciences, 6(2), 107-114.

Shin, Y. J., Hong, K. H., \& Sim, H. S. (2011). Differences in GRBAS scales and shimmer according to vocal sample types in people with vocal disorders. Phonetics and Speech Sciences, 3(3), 149-155.

Sohn, J. H. (2008). GRBAS and Voice Handicap Index. The Journal of the Korean Society of Phoniatrics and Logopedics, 19(2), 89-95.

Szkiełkowska, A., Krasnodębska, P., Miaśkiewicz, B., \& Skarżyński, H. (2018).

Electroglottography in the diagnosis of functional dysphonia. European Archives of Oto-rhino-laryngology, 275(10), 2523-2528.

Szkiełkowska, A., Krasnodębska, P., Miaśkiewicz, B., Włodarczyk, E.,
Domeracka-Kolodziej, A., \& Skarżyński, H. (2019). Mucosal wave measurements in the diagnosis of functional dysphonia. The Polish Otolaryngology, 73(6), 1-7.

Watts, C. R., \& Awan, S. N. (2011). Use of spectral/cepstral analyses for differentiating normal from hypofunctional voices in sustained vowel and continuous speech contexts. Journal of Speech, Language, and Hearing Research, 54(6), 1525-1537.

Wolfe, V., Cornell, R., \& Fitch, J. (1995). Acoustic prediction of severity in commonly occurring voice problems. Journal of Speech, Language, and Hearing Research, 38(2), 273-279.

Yoo, J. Y., Jung, O. R., Jang, T. Y., \& Ko, D. H. (2003). A correlation study among acoustic parameters of MDVP, Praat, and Dr. Speech. Korean Journal of Speech Sciences, 10(3), 29-36.

Yu, M., Choi, S. H., Choi, C. H., \& Choi, C. B. (2018). Predicting normal and pathological voice using a cepstral based acoustic index in sustained vowels versus connected speech. Communication Sciences \& Disorders, 23(4), 1055-1064.

Yui, E., Worrall, L., Lonland, J., \& Mitchell, C. (2000). Analyzing vocal quality of connected speech using Kay's computerized speech lab: a preliminary finding. Clinical Linguistics \& Phonetics, 14(4), 295-305. 
Eun-Jung Lee, et al. • Voice evaluation in Sustained Vowel and Connected Speech by Glottal Closure Pattern COMMUNICATION SCIINCES \& DISORDERS

\title{
국문초록
}

\author{
음성장애의 성대접촉 양상에 따른 모음연장발성과 연속발화의 음향학적 및 청지각적 평가 비교 \\ 이은정 ${ }^{1}$ 김재옥 \\ '노영수 이비인후과, ${ }^{2}$ 강남대학교 교육대학원 언어치료교육전공
}

배경 및 목적: 본 연구는 음성장애를 발성 시 성대접촉 양상과 후두 긴장 여부에 따라 과다기능성 음성장애(Hyper) 집단과 과소기능 성 음성장애(Hypo) 집단으로 분류한 후, 두 집단의 모음연장발성과 연속발화의 음향학적 및 청지각적 평가 차이를 비교하였다. 방법: Hyper 집단 46명과 Hypo 집단 46명이 포함되었다. 모음연장발성 /a/와 연속발화(“가을” 문단 읽기)를 통해 음성자료를 수집하였고, 수 집된 자료는 음향학적 평가를 위해 캡스트럼 분석(CPP, mean CPP F0, L/H ratio)과 청지각적 평가를 위해 GRBAS 척도로 분석되었다. 결과: 음향학적 평가에서는 $\mathrm{CPP}$ 가 연속발화보다 모음연장발성에서 높았으며, mean CPP $\mathrm{F}_{0}$ 는 연속발화에서 더 높았다. 또한 $\mathrm{Hyper}$ 집 단에서 $\mathrm{CPP}$ 가 높은 반면, mean $\mathrm{CPP} \mathrm{F}_{0}$ 는 Hypo 집단에서 높게 나타났다. 청지각적 평가에서 두 집단은 $\mathrm{B}$ 척도와 $\mathrm{A}$ 척도로 구분되었으 나, R과 S척도에서는 차이가 없었다. 두 집단 모두 GRBAS 척도는 모음연장발성과 연속발화에서 $\mathrm{CPP}$ 와 $\mathrm{L} / \mathrm{H}$ ratio와 유의한 부적 상관 관계를 나타냈다. 논의 및 결론: 본 연구는 모음연장발성과 연속발화를 함께 적용하여 음향학적 및 청지각적 음성평가를 실시할 때 성 대접촉 양상에 따른 음성장애 유형을 파악하고 성대폐쇄부전의 과다기능적 보상전략을 감별하는 데 도움이 될 수 있음을 알 수 있다. 핵심어: 음성장애, 성대접촉 양상, 모음연장발성, 연속발화, 캡스트럼 분석, 청지각적 음성평가

본 논문은 제 1 저자의 석사학위논문을 대폭 수정한 것으로 2018 년 대한민국 교육부와 한국연구재단의 지원을 받아 수행되었으며(과제번호: NRF-2018S1A5A2A03032902), 2018년 한국음성학회 가을학술대회에서 일부 발표되었음.

\section{참고문헌}

Boone, D. R., McFarlane, S. C., Von Berg, S. L., \& Zraick, R. I. (2014). 음성과음성치료(제10판, 유재연, 황영진, 한지연 역). 서울: 시그마프레스. Carole, T. F. (2014). 음성장애-이론과 실제(김성태, 표화영, 권순복 역). 서울: 박학사.

김소연, 이상혁(2017). 신경성 발성장애와 기능성 발성장애의 감별 진단. 대한후두음성언어의학회지, 28(2), 71-78.

김지성, 이동욱, 최철희, 최성희(2017). 후두마사지와 반폐쇄성도훈련이 과기능적 음성장애 환자의 음성 개선에 미치는 효과. Communication Sciences \& Disorders, 22(4), 806-817.

김향희(2005). 마비말장애 평가. 한국언어청각임상학회 언어장애 여름연수회, 23-28.

서인효, 성철재(2013). 연결발화에서 마비말화자의 음질 특성. 말소리와음성과학, 5(4), 33-41.

손진호(2008). GRBAS 음성평가와 음성장애지수. 대한음성언어의학회지, 19(2), 89-95.

신유정, 홍기환, 심현섭(2011). 음성장애와 샘플유형에 따른 GRBAS 측정치 및 shimmer 비교. 말소리와음성과학, 3(3), 149-155.

심상용, 김향희, 김재옥, 신지철(2014). 성대결절 음성 중증도에 따른 MDVP와 Praat프로그램 별 파라미터 차이. 말소리와음성과학, 6(2), 107-114. 심희정(2016). 근긴장성 발성장애와 내전형 연축성 발성장애의 판별에 대한 캡스트럼과 스펙트럼 분석의 유용성. 한림대학교 박사학위논문. 심희정, 정 훈, Lee, S. A., 최병훈, 허정화, 고도흥(2016). 내전형연축성 발성장애 음성에 대한 켑스트럼과 스펙트럼 분석. 말소리와 음성과학, 8(2), 7380.

유미옥, 최성희, 최철희, 최병흔(2018). 모음과 연결발화에서 캡스트럼 음향 지표의 정상 및 음성장애 예측. Communication Sciences \& Disorders, 23(4), 1055-1064.

유재연, 정옥란, 장태엽, 고도흥(2003). MDVP와 Praat, Dr. Speech 간의 음향학적 측정치에 관한 상관연구. 말소리와 음성과학, 10(3), 29-36. 이라희(2019). 음성장애 평가에서 CPP(Cepstral Peak Prominence)의 효과에 대한 메타분석. 충남대학교 대학원 석사학위논문 이명순, 신혜정(2010). 모음과 연속 구어에 대한 청지각 평가와 음향학적 분석에 대한 비교. 언어치료연구, 19(4), 17-37. 
이승진, 이광용, 최홍식(2018). 음성장애 선별검사 도구로서 스마트폰을 이용한 음성 녹음의 임상적 유용성. Communication Sciences \& Disorders, 23(4), 1065-1077.

이하나, 유재연, 박준희(2019). 온 · 오프라인 음성치료 프로그램이 과기능적 음성장애 환자의 음성개선에 미치는 효과: 사례연구. Communication

Sciences \& Disorders, 24(3), 814-826.

정성민, 조윤희, 홍순관, 변성완, 김은아, 손지연, 박애경(2002). 기능성 음성장애 환자에서의 음성치료의 효과. 대한후두음성언어의학회지, 145-150. 진성민(2014). 기능성 음성장애의 병태생리, 대한후두음성언어의학회지, 25(2), 75-78.

최성희, 최철희(2014). 음성 신호 분류에 따른 장애 음성의 변동률 분석, 비선형 동적 분석, 캡스트럼 분석의 유용성. 말소리와음성과학, 6(3), 63-72.

\section{ORCID}

이은정(제1저자, 언어재활사 https://orcid.org/0000-0002-4700-1989); 김재옥(교신저자, 교수 https://orcid.org/0000-0002-6504-7294) 